\title{
ANGIOEDEMA HEREDITÁRIO: UMA ATUALIZAÇÃO.
}

\author{
HEREDITARY ANGIOEDEMA: AN UPDATE.
}

DOI: $10.5380 /$ rmu.v2i1.40670

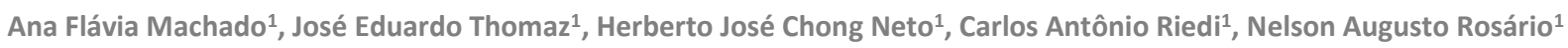

\section{RESUMO}

Objetivo: $\mathrm{O}$ angioedema hereditário é uma doença genética, de herança autossômica dominante caracterizada pela deficiência quantitativa e qualitativa do inibidor de $\mathrm{C} 1$ resultando em edema de vários órgãos. O presente estudo tem como objetivo uma revisão da literatura, visando atualização do diagnóstico, classificação e tratamento desta patologia.Método: Revisão da literatura recente de artigos originais e diretrizes nacionais e internacionais.Resultados: As manifestações clínicas de angioedema hereditário são dor abdominal, vômitos, diarreia e edema de membros, face, laringe e genitais. O diagnóstico se faz por anamnese, exame físico e exames laboratoriais, entre eles dosagem sérica de $\mathrm{C} 4$ e do inibidor da C1-esterase. A classificação é baseada na deficiência ou não da enzima $\mathrm{C} 1$ esterase. A abordagem terapêutica segue orientações gerais para evitar fatores desencadeantes, medicamentos para 0 manejo das crises e tratamento profilático. Andrógenos atenuados são utilizados para tratamento preventivo e antifibrinolíticos e plasma fresco são empregados nas crises. Novas drogas inibidoras de bradicinina e concentrados de C1 derivados de plasma têm sido utilizados no tratamento e prevenção das crises. Conclusões: $O$ angioedema hereditário é doença grave, com alta morbidade e mortalidade. O diagnóstico correto desta condição pelos profissionais da saúde é essencial para seu manejo adequado.

Palavras Chave: Angioedema Hereditário, Edema, Bradicinina, Enzima Inibidora da C1- esterase

\section{ABSTRACT}

Objective: Hereditary angioedema is a genetic disease with autosomal dominance inheritance characterized by quantitative and qualitative deficiency of $\mathrm{C} 1$ inhibitor, resulting in edema of multiples organs. The present study provides a literature review and update on diagnosis, classification and treatment of this pathology. Method: Review of recent and relevant literature, original articles and national and international guidelines. Results: Hereditary angioedema clinical manifestations are abdominal pain, vomiting, diarrhea and swelling of limbs, face, larynx and genitals. The diagnosis is made by history, physical exam and laboratory tests such as serum C4 and enzyme inhibitor C1-esterase. Classification is based on deficiency or absence of C1 esterase. Therapeutic approach follows guidelines to avoid triggering factors, medications for the management of attacks and prophylactic treatment. Androgens attenuated are used for preventive and antifibrinolytic treatment and fresh plasma are used in acute attacks. New drugs for inhibiting bradykinin and concentrated plasma-derived C1 have been used in the treatment and prevention of acute episodes. Conclusions: Hereditary angioedema is a serious disease with high morbidity and mortality. The correct diagnosis of this condition by several health professionals is essential for its proper management.

Key Words: Hereditary angioedema, edema, bradykinin, enzyme C1 esterase Inhibitor.

1- Universidade Federal do Paraná

Contato / Mail to:

Ana Flávia Machado - nanimachado@gmail.com

Serviço de Alergia e Imunologia do Hospital de Clínicas da Universidade Federal do Paraná

Rua Padre Camargo, 453. Curitiba, PR. CEP: 80060240 
INTRODUÇÃO

O angioedema hereditário (HAE) é uma doença autossômica dominante, de penetrância incompleta'. Em sua forma mais comum manifesta-se como deficiência da enzima inibidor de C1-esterase (C1-INH). Estima-se que o HAE represente $2 \%$ de todos os casos de angioedema ${ }^{1}$.

Apesar de haver discordância em relação à prevalência exata do $\mathrm{HAE}$, estima-se que seja aproximadamente de 1:50.000 ${ }^{1}$. Um dos motivos para não se obter um valor exato para a prevalência é a raridade da doença, associada à falta de conhecimento de profissionais da área da saúde. Na Espanha, onde a prevalência estimada é de 1:100.000, o tempo médio para diagnostico é de 13 anos $^{2}$.

Historicamente, o HAE foi dividido em três tipos: I, II e III. O tipo I é caracterizado por deficiência quantitativa da C1-INH; o tipo II, por deficiência qualitativa dessa enzima; e o tipo III foi associado a níveis normais de $\mathrm{C} 1-\mathrm{INH}^{1}$. Contudo, as diretrizes mais recentes apresentam uma nova classificação, em apenas dois tipos: com deficiência de C1-INH e sem deficiência de $\mathrm{C} 1-\mathrm{INH}^{3}$. O tipo com níveis séricos normais de C1-INH se subdivide em outras duas categorias: com mutação do gene do Fator XII da coagulação (FXII) e de origem desconhecida ${ }^{3}$.
A C1-INH pertence à família de inibidores da serina protease. Foram descritas mais de 200 mutações diferentes desta enzima. Menos de $20 \%$ dessas mutações são grandes inserções ou deleções do gene. Essas mutações podem causar defeito na produção da proteína, diminuindo sua dosagem sérica, ou podem resultar em proteínas com função anormal ${ }^{4}$.

A C1-INH controla diversas vias inflamatórias. Entre elas, destaca-se a via da bradicinina, na qual a enzima regula a conversão da calicreína em bradicinina ${ }^{4}$. A falha nesse processo é responsável pelas manifestações clínicas do HAE.

Outras vias afetadas são a da coagulação e do complemento. O C1-INH age na via do complemento inibindo a conversão de C1s, C1r e MASP2 (serinaprotease associada à lectina ligadora de manose 2 ) em C4 e C2, regulando sua ação. O conhecimento dessa via é importante, como será detalhado posteriormente no diagnóstico laboratorial da doença.

Na via da coagulação, o C1-INH age inibindo a ação do FXIla e do FXla, regulando a produção de plasmina e FXa. Apesar de ainda não estar claro a influência da alteração dessa cascata na fisiopatologia do $\mathrm{HAE}$, esse conhecimento pode ser relevante como foco de futuras terapias (FIGURA 1).

Figura 1: Vias inflamatórias reguladas pela enzima inibidor da C1-esterase. Adaptado de Longhurst $\mathrm{H}$, et al ${ }^{4}$

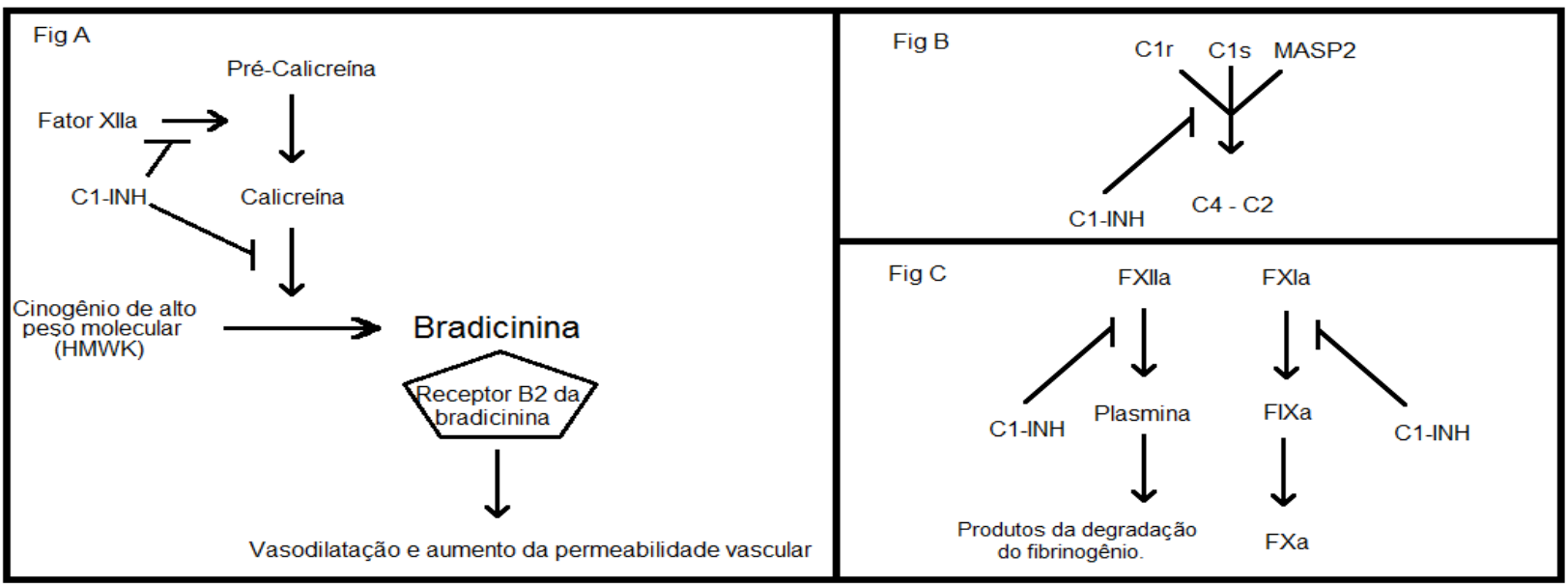

Vias inflamatórias reguladas pela enzima Inibidor da C1-esterase (C1-INH). Fig A: Via da Bradicinina. A C1-INH atua inibindo a ação do fator XII ativado que age na conversão de pré-calicraína em calicreína e também regula a clivagem de HMWK em bradicinina. No angioedema hereditário, o defeito nessa via provoca os sintomas. Fig B: Via do complemento. A C1-INH regula a proteólise de C4 e C2 a partir de dos complementos ativados de $\mathrm{C} 1 \mathrm{~s}$ e $\mathrm{C} 1 \mathrm{r}$ e da proteína serina protease ligada a lectina ligante da manose tipo 2 (MASP2). Fig C: Via da coagulação. A C1-INH inibe a formação de plasmina ao bloquear a ação do fator XII ativado e assim, evita formação de produtos da degradação do fibrinogênio. Paralelamente, inibide a ação do fator XI ativado, inibindo a ativação do fator IX que culminaria na ativação do fator $X$, previnindo a formação de trombina. 


\section{MANIFESTAÇÕES CLÍNICAS}

Pacientes com HAE apresentam-se caracteristicamente com episódios (crises) de edema de pele e de mucosas, não pruriginosos, e que podem acometer diversos órgãos. A frequência e a gravidade dos sintomas variam entre os pacientes e até $5 \%$ dos casos podem ser assintomáticos ${ }^{1}$. Apesar de já terem sido identificados alguns fatores desencadeantes, tais como estresse, pequenos traumas e procedimentos cirúrgicos, na maioria dos casos o fator que inicia os sintomas é desconhecido ${ }^{5}$.

As crises costumam se agravar nas primeiras 24 horas e tendem a se resolver espontaneamente nos dois ou três dias subsequentes. Podem existir prodrómos, tais como disfunções sensoriais (formigamento) e eritema marginatum ${ }^{6}$. Os locais mais comumente afetados são o abdome, membros, face, laringe e genitais. Entre os pacientes com HAE e alteração da enzima $\mathrm{C} 1-\mathrm{INH}$, os sintomas geralmente se iniciam na infância, entre oito e 12 anos de idade?

A dor abdominal é descrita como o sintoma mais frequente 3 , correspondendo a $50 \%$ de todas as crises de $\mathrm{HAE}^{8}$. É causada por edema de parede intestinal, que é responsável também por outros sintomas menos comuns, como vômitos e diarreia ${ }^{3}$. Estima-se que até um terço dos pacientes com $\mathrm{HAE}$ passem por algum procedimento cirúrgico desnecessário ${ }^{8}$, por confusão diagnóstica com abdome agudo.

O segundo sintoma mais comum é o edema de membros, afetando até $96 \%$ dos pacientes ${ }^{8}$. Apesar de não ser motivo de internação, o edema de membros é bastante doloroso e limitante. Tarefas simples, como dirigir ou usar o celular, podem ser impossibilitadas ${ }^{8}$.

$O$ edema de face é um sintoma comum entre pacientes com HAE, podendo ocorrer edema de língua ${ }^{9}$. O edema de laringe, apesar de menos frequente, é a condição responsável pela maior parte das mortes por HAE. Estima-se que cinquenta por cento dos pacientes terão ao menos um episódio durante a vida, com risco de asfixia ${ }^{8}$.

O edema de órgãos genitais pode afetar tanto homens quanto mulheres. Um terço dos pacientes podem ter episódios de aumento de bolsa escrotal ou de lábios vaginais ${ }^{8}$. (Figura 2 e 3)

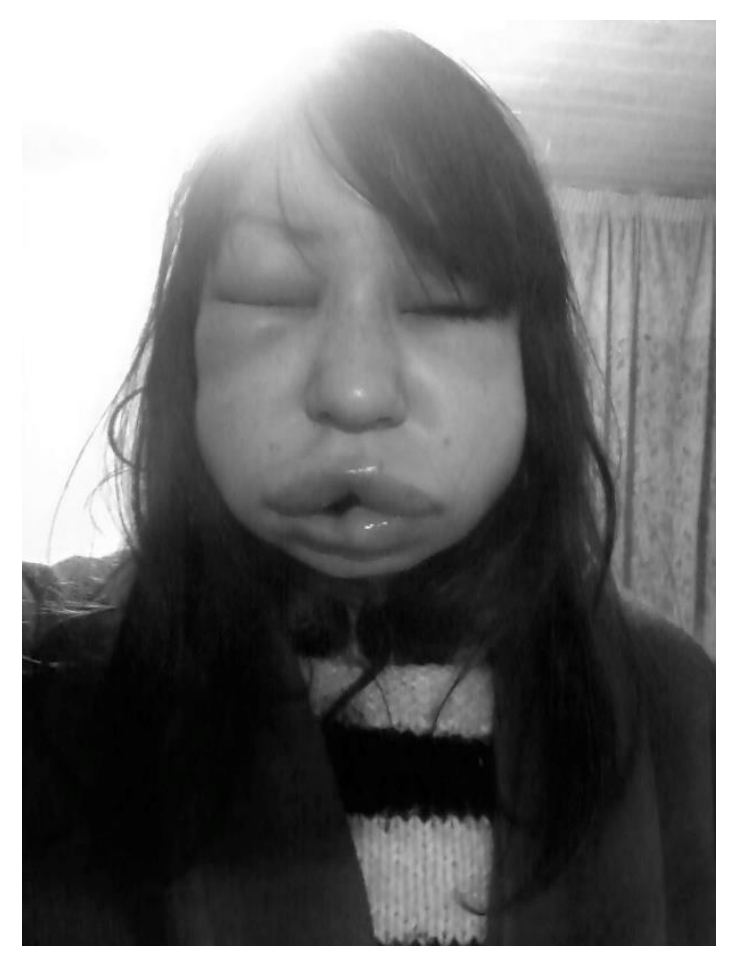

Figura 2: Angioedema de pálpebras e lábios. Fonte: 0 autor

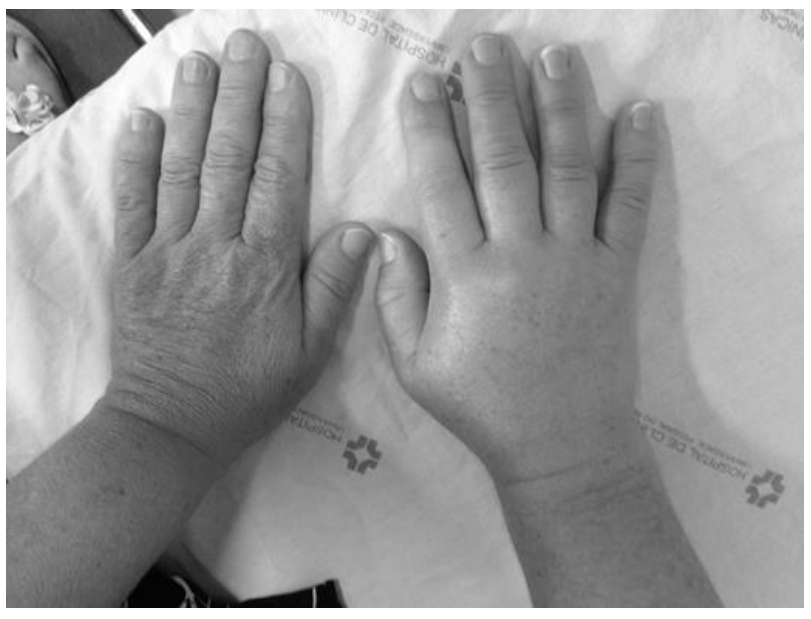

Figura 3: Angioedema de mão. Fonte: O autor

\section{DIAGNÓSTICO}

O diagnóstico é confirmado após anamnese, exame físico e exames laboratoriais. A anamnese deve ser detalhada e deve responder aos seguintes quesitos: tempo de início dos sintomas e da crise atual, história pregressa de crises de edema de quaisquer localizações, idade na primeira crise, tempo médio de duração de crises, intervalo de tempo entre crises, sintomas prodrômicos, possíveis fatores desencadeantes, inquérito nutricional, consumo de 
bebidas, medicamentos e suplementos nas 24 horas prévias à crise e história familiar de edema recorrente ${ }^{10}$.

Deve-se observar que cerca de um quarto dos casos não apresenta história familiar positiva, admitindo-se tratar de mutações de novo. Outra particularidade é a idade de inicio dos sintomas. É comum que os sintomas se iniciem na infância quando o HAE está associado a alterações na enzima C1-INH. O HAE relacionado a níveis normais dessa enzima, por outro lado, tende a se manifestar mais tardiamente e muitas vezes pode estar associado a níveis elevados de estrogênio ${ }^{1}$. Neste caso, os sintomas podem ser agravados ou desencadeados por anticoncepcionais orais ou por gravidez ${ }^{11}$. O eritema marginatum não é característico do HAE relacionado a níveis normais de C1-INH, sendo indicativo de alteração da função dessa enzima9.

Ao exame físico, deve-se examinar detalhadamente a pele e a cavidade orofaríngea e confirmar a ausência de urticária e prurido. A gravidade e extensão do edema devem ser quantificados. No angioedema intestinal, a dor pode ser generalizada ou localizada, com aumento ou diminuição dos ruídos hidroaéreos. Em alguns casos ascite pode estar presente ${ }^{10}$.

$\mathrm{Na}$ investigação laboratorial, o primeiro exame a ser solicitado é a dosagem sérica de C4. Caso esteja diminuída, indica deficiência da C1-INH. Para confirmação diagnóstica, mede-se o nível sérico de C1INH, que deve estar $50 \%$ abaixo dos valores de referência. Caso os níveis séricos de C1-INH estejam normais, deve-se investigar deficiências funcionais dessa enzima ${ }^{3}$.

No caso de níveis séricos de C4 normais, as hipóteses apontam para angioedema com níveis de C1IHN normais ou angioedema adquirido. Os critérios diagnósticos para o tipo de C1-INH normal são: sintomas clínicos característicos de $\mathrm{HAE}$; um ou mais familiares com sintomas característicos; exclusão da forma familiar e hereditária de urticária crônica associada a angioedema; níveis séricos de atividade de C1-INH normais. Para diferenciar os subtipos associado ao FXII e de origem desconhecida, deve-se atentar à presença ou ausência de mutação associada ao HAE do subtipo FXII ${ }^{3}$. (Figura 4).

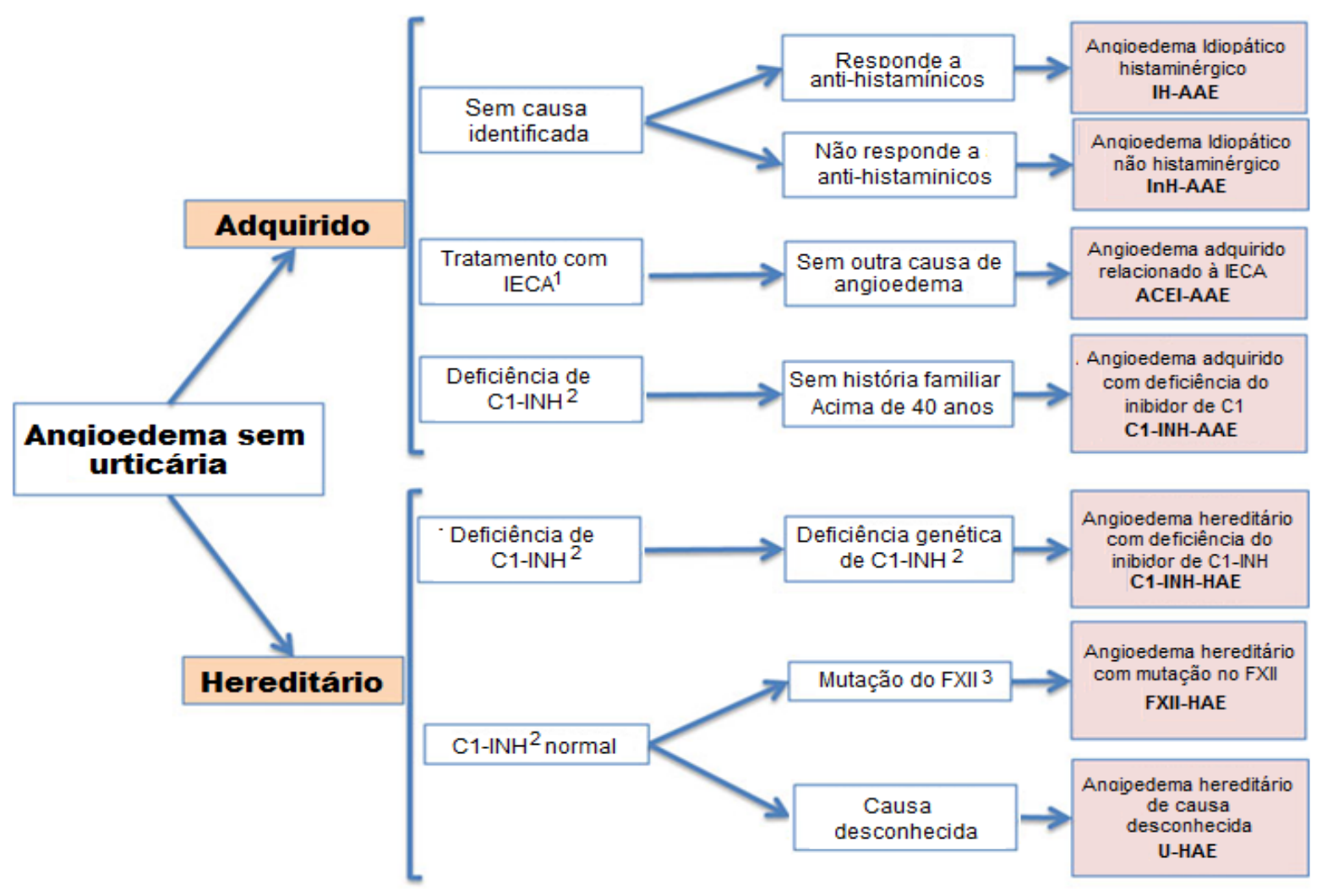

Fluxograma representando a classificação dos angioedemas sem urticária, de acordo com as novas diretrizes. 1. IECA: classe de medicamentos inibidores da enzima conversora da angiotensina. 2. C1-INH: enzima inibidora da C1-esterase. 3. FXII: gene do fator XII da coagulação.

Figura 4: Classificação dos angioedemas sem urticária. Adaptado de Cicardi M, et al ${ }^{3}$ 


\section{TRATAMENTO}

A abordagem terapêutica pode ser medicamentosa ou não medicamentosa. $\mathrm{Na}$ abordagem não medicamentosa, são fornecidas orientações gerais sobre o curso da doença e fatores desencadeantes ${ }^{1}$. Os principais fatores identificados são traumas mecânicos, estresse e infecções. Deve-se tomar cuidado com a puberdade e outras situações de alteração hormonal, bem como deve ser evitado o uso de contraceptivos a base de estrogênio. Atividade física devem ser praticada regularmente, porém deve-se evitar esportes de impacto ${ }^{12}$.

O tratamento medicamentoso é diferente das outras formas de angioedema, por se tratar de um processo inflamatório mediado via bradicinina. Antihistamínicos e corticoides não são efetivos no HAE. A terapêutica se divide em profilática e de manejo das crises. O tratamento profilático para HAE é indicado em pacientes que tem ataques frequentes e graves ou com angioedema de vias aéreas superiores. Também está indicado na proximidade de evento estressante, como por exemplo, um procedimento cirúrgico ou dentário ${ }^{8}$. Os andrógenos atenuados constituem-se na terapêutica mais eficaz e mais bem tolerada para profilaxia a longo prazo do HAE. Agem aumentando os níveis do C1-INH e da fração C4 do complemento e, como consequência, reduzem as crises de angioedema. O danazol é o andrógeno atenuado mais frequentemente utilizado em nosso país para o tratamento do $\mathrm{HAE}^{8}$. Estima-se que até $50 \%$ da população brasileira com este diagnóstico utilize a medicação ${ }^{13}$. Contudo, o danazol é contraindicado em gestantes e crianças $^{14}$. Nestas, seus efeitos colaterais incluem fechamento precoce de epífises ósseas (resultando em baixa estatura) e virilização ${ }^{15}$. As pacientes em idade fértil devem ser advertidas sobre os riscos e que necessitam de troca de medicação durante a gestação ${ }^{11}$. A dose recomendada de danazol não deve exceder $200 \mathrm{mg} /$ dia. Recomenda-se vigilância a alguns eventos adversos, como hepatoxicidade, virilização, dislipidemia, hipertensão e hematuria. Há relatos de adenomas hepáticos e carcinomas hepatocelulares associados ao uso prolongado de danazol. Por isso, dosagem de enzimas hepáticas e ultrassonografia semestral do fígado são recomendadas ${ }^{1}$.

Em casos leves ou apenas com edema periférico, o tratamento profilático não é obrigatório', sendo indicado apenas o manejo agudo da crise. No Brasil, a principal droga utilizada é o ácido tranexâmico, que pode ser utilizado por via oral, possibilitando ao paciente autoadministração quando necessário. Apesar de eficaz para a maioria dos sintomas, apresenta como desvantagem tempo de inicio de ação longo, em média de $12 \mathrm{~h}^{16}$. Em muitos países, a terapia com ácido tranexâmico já foi quase completamente substituída por outras drogas, com tempo de inicio de ação mais curto, como o antagonista do receptor de bradicinina e o concentrado do inibidor de $\mathrm{C}^{15}$, apenas recentemente disponíveis no Brasil ${ }^{13}$. Como opção, pode-se utilizar também o plasma fresco. Este, apesar de controlar as crises, apresenta uma série de efeitos adversos graves, podendo inclusive piorar o quadro agudo ${ }^{1}$. Também não é passível de autoadministração, o que exige do paciente procura por serviço médico especializado ${ }^{15}$.

A opção terapêutica mais indicada atualmente é o antagonista do receptor de bradicinina tipo II, o icatibanto'. É um medicamento de injeção subcutânea que permite administração pelo próprio paciente, em seu domicílio'. Estudos apontam que a eficácia do icatibanto chega à $90 \%$ das crises, com tempo médio de inicio de ação de 48 minutos e de resolução total do quadro em duas horas ${ }^{16}$. Desta forma, reduz custos com internamentos, previne óbitos e devolve a autonomia e qualidade de vida aos pacientes ${ }^{17}$.

\section{Acompanhamento e prognóstico}

O HAE é uma doença crônica que exige acompanhamento vitalício. Recomenda-se ao paciente uso de diários para documentar frequência, duração e características de crises, bem como para registro do uso de medicamentos e seus possíveis efeitos colaterais $^{12}$.

O prognóstico tem melhorado com o desenvolvimento e oferta de novas terapêuticas. Um grande desafio ainda presente é a dificuldade diagnóstica do $\mathrm{HAE}$, que aumenta a morbi-mortalidade desta condição clínica. Como alerta, sugere-se incluir o HAE no diferencial de crises de angioedema que não sejam responsivas a anti-histamínicos e corticoides ${ }^{3}$.

\section{CONCLUSÃO}

O HAE, apesar de raro, é uma entidade que provoca sofrimento importante e pode levar ao óbito. A falta de conhecimento e o subdiagnostico são alguns dos principais obstáculos a serem enfrentados. Não são incomuns cirurgias abdominais desnecessárias ou história de abuso de medicamentos anti-histamínicos e de corticoides. O profissional da saúde deve estar atento à existência dessa doença, para realização de diagnóstico precoce e instituição de terapêutica adequada. 


\section{REVISTA MÉDICA DA UFPR}

\section{REFERÊNCIAS BIBLIOGRÁFICAS}

1. Giavina-Bianchi P, França AT, Grumach AS, Motta AA, Fernandes FR, Campos RA, et al. Diretrizes do diagnóstico e tratamento do angioedema hereditário. Rev bras alerg imunopatol. 2010;33(6): 242-52.

2. Lumry WR. Overview of Epidemiology, Pathophysiology, and Disease Progression in Hereditary Angioedema. The American Journal of Managed Care. 2013;19: S103-10.

3. Cicardi M, Aberer W, Banerji A, Bas M, Bernstein JA, Bork $\mathrm{K}$, et al. Classification, diagnosis, and approach to treatment for angioedema: consensus report from Hereditary Angioedema International Working Group. Allergy 2014; 69: 602-16.

4. Longhurst $\mathrm{H}$, Cicardi $\mathrm{M}$. Hereditary angio-oedema. Lancet, 2012; 379: 474-81.

5. Toscani M, Rield M, Geffen D. Meeting the Challenges and Burdens Associated With Hereditary Angioedema. Managed Care. 2011;20: 44-51.

6. Zuraw BL. Clinical practice: hereditary angioedema. N Eng J Med. 2008;359: 1027-33.

7. Ebo DG. Hereditary angioedema in childhood: an approach to management. Pediatr Drugs 2010;12: 257-68.

8. Tse K, Zuraw BL. Recognizing and managing hereditary angioedema. Cleveland Clinic Journal of Medicine 2013;80: 297-308.

9. Miranda AR, de Ue APF, Sabbag DV, Furlani WJ, de Souza PK, Rotta O. Hereditary angioedema type III (estrogen-dependent) reporto $f$ three cases and literature review. An Bras Dermatol 2013, 88(4):
10. Nzeako UC, Longhurst HJ. Many faces of angioedema: focus on the diagnosis and management of abdominal manifestations of hereditary angioedema. European Journal of Gastroenterology \& Hepatology. 2012;24: 353-361.

11. Bouillet L, Gompel A. Hereditary Angioedema in Women Immunnol Allergy Clin N AM 2013;33: 505-11.

12. Hsu D, Shaker M. An update on hereditary angioedema. Curr Opin Pediatr. 2012;24(5): 638-46.

13. Lang DM, Aberer W, Bernstein JA, Chng HH, Grumach AS, Hide $\mathrm{M}$, et al. International consensus on hereditary and acquired angioedema. Ann Allergy Asthma Immunol 2012;109: 395-402.

14. Riedl M. Hereditary Angioedema Therapies in the United States: Movement Toward an International Treatment Consensus. Clinical Therapeutics 2012;34: 623-30.

15. Sardana N, Craig TJ. Recent Advances in Management and Treatment of Hereditary Angioedema. Pediatrics 2011;128: 1173-80

16. Cicardi M, Banerji A, Bracho F, Malbrán A, Rosenkranz B, Riedl $M$, et al. Icatibant, a new bradykinin-receptor antagonist, in hereditary angioedema. N Engl J Med 2010;363: 523 -31.

17. Boccon-Gibod I, Bouillet LL. Safety and efficacy of icatibant self-administration for acute hereditary angioedema. Clin Exp Immunol 2012;168(3): 303-7. 